The rational alternative is to list specific problem areas in the patient's personality, giving appropriate examples. While this entails more time and effort than simply stating personality disorder (or more usually just 'p.d.'), it at least suggests a basis for treatment directed at specific areas of difficulty.

Concerning the practice of omitting personality disorder as a diagnosis from patients' notes in case they see them, it should be clear that the approach outlined above makes this unnecessary as it has much less potential to give offence. For example, if you point out to patients that they have difficulty controlling their anger, act impulsively and find it difficult to empathise with others - giving examples from their history, then they will probably agree with you and indeed may be impressed by your insight. Tell them that they are a psychopath however and you will not get the same reaction.

Dr Steadman felt confident in discharging a 'drunk' patient after reading the diagnosis personality disorder in the notes. But what confidence does such a label give us? It must be remembered that alcoholism and personality disorder are risk factors in both completed suicide and deliberate self harm, that patients with personality disorders may develop mental illnesses requiring hospital treatment, and that there is a duty of the doctor to act in the patient's best interests. Psychiatric diagnoses can also change over time.

I am sure Dr Steadman was correct to discharge his patient, but such decisions should be made on the basis of assessment at the time. Previous notes are useful as a guide to management, but past diagnoses should be treated with suspicion, and should have little bearing on decisions in the emergency situation.

ADAM KIRBY, Southport and Formby Communtty Health Services NHS Trust, Hesketh Centre, 51-55 Albert Road, Southport PR9 OLT

\section{Training, manpower and employment in Australia}

Sir: It was interesting to read Dr Kisely's article about psychiatric manpower and training in Australia (Psychiatric Bulletin, 1993, 17, 669671) from my perspective as a British psychiatry trainee currently two months into a one year exchange post in Sydney.

Dr Kisely does not state from what perspective he has written his article - whether as an Australian working in Britain or vice versa however, I would think he has not worked in New South Wales. It is important to emphasise that there are marked differences between the six states and two territories in terms of mental health legislation service provision and arrangements for medical registration.

While Dr Kisely comments that arrangements for temporary work experience as part of training remain relatively straightforward. I found that arranging my visa and medical registration to work in Sydney time and finance consuming and, although hospitals in New South Wales may be happy to employ a British psychiatry trainee, the Immigration Department and Medical Board of NSW do not make things easy for them. The Medical Board of NSW grant "registration with conditions" when the applicant is exchanging work with an Australian psychiatric trainee or when the applicant can make a case that he or she is furthering his or her training by working in a designated post in New South Wales. When the Board have approved the position on the basis of these criteria the applicant can apply for a temporary residence visa which allows him or her to work on arrival in Australia. The applicant then has to present him or herself to the Board with documents and photographs and a cheque for $\$$ A275.00 in order to gain a registration certificate which allows him or her to work only in the post to which he or she has originally applied for, and which disallows him or her from doing any private work, working as a locum or working in any other post. It is therefore a time consuming process with a number of potential stumbling blocks.

I would encourage trainees to come and work in NSW but I would advise them to make plans well in advance and to inform themselves fully of their prospective conditions of service.

AlCUIN WILKIE, Westmead Hospital, Westmead NSW 2145, Australia

\section{Case conferences: an essential part of training in psychiatry}

Sir: Rowlands \& Geddes (Psychiatric Bulletin, 1993, 17, 363-364) emphasise the importance of journal clubs in the education of psychiatric trainees. Case conferences are a similarly important part of psychiatric training. It is recommended that such conferences take place weekly for a minimum of 30 weeks in the year (Royal College of Psychiatrists, 1987). It is therefore surprising that little attention has been paid to the subject in the psychiatric literature. Case conferences are an excellent way to learn presentation and interview skills. In addition they provide a forum for sharing knowledge and experience about the diagnosis and treatment of mental illness. Standard formats for presenting a case have been described (Vincenti, 1990; Holden, 1987). Sadly, at the 